\title{
Chhaupadi Pratha: Women's Experiences and Perceptions about Social Suffering
}

\author{
Nirajan Khadka*
}

\begin{abstract}
Chhaupadi Pratha, a socio-cultural system, is mostly exercised at the Far Western region of Nepal. The system is linked with biological process of women's menstrual period. Women are kept in small sheds away from home during their menstrual period. Besides difficulties staying in a small hut, they have to suffer from many physical and psychological problems. In that period, they are not allowed to take part in religious ceremonies, family kitchen for nutritious food, and family home for security, and warm. This article attempts to analyze women's experience and perception towards Chhaupadi system. In doing so, it investigates how women are suffering from the Chhaupadi system and its consequences. This ethnographic research employed unstructured in-depth conversations and key informant interviews methods to collect information. This research finds that these women are affected physically and mentally by the practices of Chhaupadi. The practice restricts women's safe live and educational opportunity because they are restricted touching anything during their period. The concept of pollution and purity differentiate the life situation of women which is depended on monthly menstrual bleeding. Menstruating women are believed as polluted that's why they are forced to live small shed and face various difficulties. Non-menstruating women are believed as a pure. Consequently, their social relationship disturbed by shame and restriction. Living in the Chhaupadi shed brings psychological and physical threats. The discrimination during the periods faced by women is considered as violation of fundamental human rights. Women activists are engaged in campaign against the system.
\end{abstract}

Keywords: Chhaupadi, menstruation, health, suffering, women, perception

\section{Introduction}

In most parts of the developed world, women are assumed that their menstrual period remain a part of their private lives, and it does not affect their ability to work, go

\footnotetext{
${ }^{*}$ Mr. Khadka has completed MPhil in Anthropology from Tribhuvan University, Nepal, and has been working in development fields in various organizations.
} 
to school, or contribute to society(Kandel et al, n.d.). In Nepal, menstruated women are considered "polluted" and "impure". During their menstrual period, they are avoided from participating everyday routine lives. Their restriction is socially influenced in their private issue. Even in this modern-time, women and girls are sent to spend the duration of their monthly menstruation periods isolated in an unsanitary shed; this is a common and accepted ritualistic practice for women (Manzullo, 2011).This system is known as Chhaupadi Pratha in which women and girls are restricted to touch anything and have to live in small shed during menstruation. It is a normal practice prevalent in the FarWest and some parts of the Mid-West region in Nepal (Kindle et al, n. d.).

It is common for women who are regarded as 'impure' and untouchable during their menstruation (Maharjan, 2010). Everything they touch during their menstruation days considered as impure (Mazzulo, 2011). The word Chhaupadi came from the Achhami local language word. Chhau means menstruation and Padi means woman (Kandel et al, n. d.). Chhaupadi means "Menstruating woman." The Chhaupadi is a practice of keeping women and girls outside the house in a separate small and dark place known as Chhau-goth (Dahal et al, 2017). However, they are isolated from family, relatives, and society as well.

Centuries old Chaupadi system of ritual has been banishing Nepali women and girls at the time of menstruation. The history of menstruation is considered to be followed from religious description where it was believed that Gods and Goddesses became angry with women who stay with the family at house during menstruation. Based on the religious folklore, Indra, the King of Heaven, was accused of killing a Brahmin (Hussain, 2012). For him, because of the illicit acts with women, the Indra committed during his quest to redeem his sin, for these acts all women were ordered to be punished through menstruation. There are direct religious aspects for following practices. When, a Hindu woman reaches in maturity, she is kept in a dark room for thirteen days during their first and second menstrual cycle and four days of every other menstrual cycle ((Kandel et al, n.d.). In the case of woman who have baby, she has to stay in shed for five days and married woman has to stay for only four days (Maharjan, 2010).

\section{Objectives and Methodology}

The general objective of this study is to analyze women's perceptions and experiences about Chhaupadi system. Specifically, the objectives of this study are to describe women condition in the process of Chhaupadi Pratha and to investigate the women's experience and perception towards Chhaupadi system.

The research was conducted from Chaurpati Rural Municipality ward no. 6 Duni village in Achham. The study was based on descriptive research design and qualitative 
by nature. For this study, I used in-depth interviews, group discussion, observation, and oral history methods to collect information. The secondary literatures are also reviewed.

\section{Ideology of pollution and purity}

Menstrual bleeding is believed an extreme impurity in Chhaupadi system and discriminatory menstrual practice is imposed on women (KC, 2018). The concept of pollution and Purity are central idea of caste and gender (Bennet, 1983). Through the gender perspectives women are believed as impure or polluted during their monthly periods by women and men also. The ideology of purity-pollution is related to states of peoples, objects, and actions (Douglas, 1966). Likewise, the women were decided purepollute by their monthly states and action following that idea. In every society, there are concepts of purity and pollution. Both of them exist at the same time in which purity makes social order and pollution brings disturbance in social order (Bennet, 1983). During Chhaupadi, women are treated as bodily polluted during the period of menstruation. In the case of Achham, most of the social relations of the people directed by the idea of purity and pollution. There were various actors to define the practices of purity and pollution. They were shaman (Dhami), the regular worshiper (Pujari), and the priest (Brahaman), who has strictly abided by the norms of impurity avoidance. They forced to follow the Chhaupadi system by making the norms of impurity avoidance. For them, menstruation is considered contamination of body. About impurity Kali BK (name changed) said, "Chau bhaya pachhi baikinika hada bati ragat aaudochha tei ragat le nachhunya banaunya ho, pan dinka dini ragat aauna banda vaya pachhi baikini gaiko gaut khayera chokhkhinichhan" (when a woman menstruates, the blood comes out from the body that blood makes women untouchable. After five days, the blood stops to come out then they become pure or touchable after drinking cow's urine.)

\section{Women's Condition in Chhaupadi System}

Chhaupadi practice was running based on the belief that when woman has her monthly period, she herself feels "impure" and "pollute" and "contaminate" the staying outside the house during her menstruation periods (Rebaud, 2011). Women were socialized such a way that they themselves believed the biological process of menstruation was polluted. They have to follow the system because it becomes general norms. In the strictest observation of Chhaupadi, the women are prevented from looking at the sun, interacting with other family, and community members. They are restricted having dairy products and conducting their regular activities. These restrictions make women detached from the various things in the society that caused the mental torture. Furthermore, the women are badly treated in the community because it 
is believed that if they touch the fruit trees, the fruits will fall before ripen time or the fruits tree will dry. It is also believed that if the menstruate woman touches the source of water, the water source will dry up; if the cattle are fed or milked by her, blood will come out of their teats instead of milk (Rebaud, 2011). Believing in these things, women felt discriminated and deprived from the common daily activities. It is believed that menstruating woman cannot touch anyone; if anyone touches her, they need to be purified by taking a bath and drinking cow's urine. This is the process that brings people impurity to purity. Biologically, menstruating woman needs rest but in the case of Chhaupadi system woman has to engaged in hard labor, such as working in the farms, collecting firewood, washing clothes, and so on (Sharma, 2010). It is believed that if the woman does not follow these practices, there could be different of negative impacts such as she could become sick or even dies; her bones could break; she could become infertile; other family members could fall ill or even die (Kandel et al, n. d.). These are hidden forced to follow the system.

During the interaction with Tulasa Auji (name changed), she shared her bitter experiences. Each month, during her menstruation, she had to stay in small shed. She asked herself "Oh God! Why have you given this torture to the women?" Her experience of staying in the shed is so horrible. She is even obligated to take her meals in this unclean place. Likewise, Mrs. Dhana BK also has to stay in her menstrual hut. Because of poverty, the community cannot construct another shelter for use as Chhau shed. If they touch something accidentally, then the item should be cleaned immediately. If the women touch their husband or other family members, then they must bathe to clean themselves. During this period, she felt as if she was treated an animal and, for this reason, she wanted to share her experience.

\section{Housing Pattern for Chhaupadi}

Housing pattern of Chhaupadi Goths found different in different community and geographical area. Many of the Chhaupadi goths are built within the household premises, but in other cases, they are built far from the homes, up to hundred meters away from the houses (Amgain, 2011). It was found that the space of Goth could not adjust more than two women but more than two women stayed in a hut. The hut was constructed about four feet long, four feet wide, and four feet height. It was made of mud, stone, and wood. There was no windows and ventilation. A Chhaupadi shed, generally, is built from stone, grass and stick. The sheds found very unhygienic, airless and poorly built. During their stay at shed, they did not use sufficient clothes and utensils because they were not allowed pollute more clothes and pots. After period, they have to purify these clothes and pots. They cannot stand within the shed. The Chhaupadi sheds were filthy floors. The dung and other wastes were collected in front 
of the shed. Because of the congested shelter and poor sanitary conditions, women were left, completely separated that cause issues of life threatening. If a woman has physical problems during monthly periods, she could not get any chance to get help from family and community. This may be a cause of death. About Chhaupadi Goth Naru Saud (name changed) said, "Goth ghar dhekhi alli para saguro adhyaro hudochha naap thauma pana tin char jana suttachhan" (The shed is constructed a little far from the house with narrow space and three or four persons should stay there.)

\section{Belief of Chhaupadi Pratha}

Chhaupadi is such a traditional practice that has been in existence that banishes women from their house during their menstrual bleeding and this practice is derived from a Hindu tradition related to association with menstruation (Katarina \& Are, 2015).Many social and cultural beliefs reflect a gender bias and discriminatory attitude by considering menstrual blood is polluted and impure (Joshi, 2015). Chhaupadi practice has been widely recognized as a social norm in some communities of Hindu society in Nepal through religious rituals (Acharya, 2017). The most ordinary cultural belief demonstrated by the respondents was that women are considered polluted and untouchable during the period (Lama \& Kamraj, 2015). There was a belief that, if a woman touched so-called sacred thing during her menstruation period, then it would happen disaster such as cholera, diarrhea, landslides, heavy rain, etc. If anyone doesn't follow the norms of Chhaupadi, the society will face premature death and some suddenly accident. The local beliefs about Chhaupadi are related with health, illness and death. There are many narratives of improper Chhaupadi and illness and deaths of people. For instance, Devi Luhar (name changed) said, "Chhaupadiko chalanlaina manya pachhi hunyana hunya biram lagdachhan, saap kattochha, deota risai anikaal lagdochha, gai goruko nuksan hudoch ha" (if we don't follow the tradition of Chhaupadi, there will expand unknown lines in the community; snake will bite, deity will become angry, there seems scarcity of food, cases of premature death of girls, and sickness and death of cattle.)

There is a popular narrative in Patalkot, one of the joined villages of the research. Shanti higher secondary school is located near the temple of Goddess Durga named Sannitkot in the village. So-called lower castes (Dalits) and the menstruating women were prohibited to enter the temple. If they break the tradition and enter the temple, they will face various problems such as madness, death, and faint.

\section{Food Behavior and Work Burden}

All the Chhaupadi women I have talked with were not allowed having dairy product. They were not allowed eating meat of offered goats, buffalos, hens and ducks 
in temple during the festival. They did not touch fruit trees. They ate rice, daal, vegetable and chapatti during their monthly period. Answering my question Narpata Saud (name changed) says, if they drink milk, the cow or buffalo will not give milk. And answering my question The Champak Sonar (name changed) said, "Chhau bhyaka bela dud, dai, chhai, ghiu kei khana millaina sukhkha bhat daal tartari matrai khana paidochha, kasai deotalai chdayaka kukuda bakhrako masu pana khana millaina, khaya pachhi deota risauchha". (If Chhaupadi women eat offered animals, the god will be angry so badly that their life will be lost. They have to participate in hard labor out of the house, such as, farm work firewood collection, washing clothes, and so on.") Chameli Kami (name changed) said that; "Aba Chhau bhayaka bela hamle ghar bhitrako sajilo kaam harna millaina, ghar bairako ghas katnya, daura lyaunya, khannya, syaula lyaunya jasa kaam harnu paddochha."(During the menstruation period, we are not allowed to be engaged in easy work within the house. We should be engaged in hard work outside such as grass cutting, firewood collection, field digging etc.)

Most of the Chhaupadi women I have talked were living at the small shed far from their home. They didn't allow entering home and cooking food for their family. The women were not allowed to take part on religious ceremonies. I observed that some menstruating women did not participate in local rituals called Bhuwa. They have to bathe every day and wash clothes by using cold water. Moreover, there was small separate tape and well for menstruating women. This tape and well not used by common people.

\section{Dharma and Paap}

Chhaupadi practice is associated with Hindu Dharma, which illustrated that the menstruation as a "curse," and menstruating woman as "impure, "even though menstruating women are prohibited from usual religious ceremonies, including entering home, prayer rooms and the temples (Amity et al., 2018).Once, I asked to a woman, (name changed Kabita Saud) what happens, if you go inside the house during menstruation. She shared me that it was a sinful act (Paap lagne kaam ho). "I cannot do like that and if I did that my cows and buffalo will be ill and tiger can take goat from the cowsheds". Many girls and women follow the tradition in the name of Dharma. They thought that following the tradition was a Dharma (main duty) of them. If they break the rule of Chhaupadi, their Dharma will be destroyed. Violation of Dharma also a sinful act (Paap Lagchha). If dairy product such as milk, curd, and ghee are given to the girls and women of period, who come in contact with religious place, fruit-bearing trees, then it is considered as sin (Paap) (Kandel, Bhandari and Lamichanne, n. d.). The most of the women and girls do not want to be a sinful (paapi) by violating the Chhaupadi rules 
and other family members do not want to take the risk. The concept of Dharma and Paap embedded in local social structure is a driving force to continue the Chhaupadi practice in the region. Similarly Desara Luhar (name changed) said, "Chhaupadi gotha nabasi khera gharai basya pachhi pada ni deotako than hudochha taludi Chhaupadi bays pachhi deota risaudachhan, paap lagdochha, chhal hudochha, gothaka goru maddachhan bana bakhralai bag khadochha, gharaka maisa birami paddachhan" (if she stays at home during the period, the god from the upper room of the house will be angry, then, she will have bear $\sin$ (Paap). It will harm to family member and castles.)

Tuli Auji (name changed) said to me that they had to face various difficulties if not followed Chhaupadi system. For her, Chhaupadi is sinful (Paap Lagchha. She shared me a story that she had herded. She Said "A woman was not following the system in the village. In the menstruation period, she lived inside the home, drunk dairy products, went anywhere through the way of temple. One day her son went to a jungle to gather fire wood. Then, a tiger attacked and killed her son. She relates the story with the consequences of not following Chhaupadi. It was considered a cause of bearing sin (Paap Lagyo).

\section{Shamanism (Dhami-Jhakri)}

Shamanism is the process of Dhami-Jhakri. It is believed on supernatural power. The Chhaupadi system is associated with Dhami-Jhakri system. Dhamis-Jhakris are local religious leader, a representative of god. So, everybody followed their rules of Chhaupadi. They were the main illustrator of myth and superstition. Dhami-Jhakri is also a reason for following the system. According to a local Dhami, if woman doesn't follow Chhaupadi process, the God (Deota) will be angry (Risauchha). The Dhami might fall sick, and the Dhami's neck will bend on the back side. Sometimes, he might become faint. It accelerates the belief that menstrual women should not come in contact with sacred things once set on the processes of evolution of different socio-political systems (Amgain, 2011). An old women shared me a narrative that, "If someone is feeling suffering from any problems, if one's buffalo left to give the milk then he or she goes for Dhami to ask what happened to them, then Dhami shack and blame the break of Chhaupadi process. So, the Dhami, the symbol of local deity, who exercises the power of deity, plays roles for the perpetuation of the Chhaupadi rules.

A younger girl responded that the women followed the tradition because of the fear of local deity (Dhami/Deota). For them, many people's life depends on the power of local deity during natural disaster. Many people believe that they will be saved from many unfortunate happenings because the power of their local deity. The person, who invoked some supernatural power, made be shacking the Dhami during religious functions and gatherings. They are considered as pure people. They have to maintain 
the contact of bodily impure people such as Dalit and Chhaupadi women. So-called pure Dhamis and Jhakris do not eat the meal made by polluted hand. In the case of Chhau, they do not walk the way from where the menstruated walked. Once, I asked with a woman about Dhami, what would happen if a girl or woman touches him during the period of menstruation, she said, "Chhaupadi baikini chhau bhyaka bela dhamika hada lagya pachhi deota risaudach han tabai dhami birami paddachhan, tei baikini lai pana baulyaudochha". (if menstruating women touched the Dhami, the god would be angry, the Dhami would get sick and the woman would shake her body.)

Pārbati Saud (name changed) shared me an incident. There was a big stone in front of her house. It is believed that the god (Deota) lives on the stone menstruating women were prohibited to touch and go near the stone. A couple of days ago, she was bringing the grass for cattle. There was raining and the grass become wet. Her sister kept the grass on the big stone. The grass brought by her touched the stone. She was menstruating. Then, the god (Deota) had been angry. The big snake, as a symbol of god, was standing in front of her house. Then after, her mother-in-law visited there and apologized to the snake by saying, "Please god forgives us! It was our big fault! We will never do such acts!" Then, the snake went and disappeared slowly far from the house. The incident reflects the strict belief upon Shamanic interpretation of menstruation.

\section{Women's Perceptions}

Most of the women with whom I talked to interpret the Chhaupadi practice shared stories of Hindu culture. Menstruation is a form of taboos and stigma. They feel that, menstruation is harmful for them and their family till not following the system. They believed that if didn't maintain this tradition; the community would no longer be able to survive. A Dalit woman shared her story of her first menstruation. At the first, she felt shyness to share with her family members. Her friend shared the case with her mummy. After that, she was separated from her family. She was kept in a small dark shed where she never been. In this period, she felts suffocation in a small sheds. She could not sleep whole night and became mentally unstable thinking of security and biological change. After completing the periods, she could not show up her face to the male family member thinking that she had committed sinful act. Women of Duni revealed that staying in Chhaupadi shed was very challenging because there might happens many accidents such as snake bite, wild animals attack and possibility of rape. These are cause of fear staying at the Chhau shed. Some women revealed that having bathe and washing cloth early in winter morning with cold water was challenging task.

A woman Kabita Saud (name changed) shared that when she started to live in shed for her menstruation, it was very uncomfortable situation than staying at home she 
faced. For her, she can be most insecure from various things in shed also. She alienated from family and community. That's why she has suffered mentally and physically. Women to whom I talked have known that in their monthly period, they need more supports, but in case of Chhaupadi, there are restricted from all support. This is very torturing for women. Despite knowing the entire thing, they cannot do anything because they are quite being afraid from local cultural belief. An old Dhauli Saud (name changed) woman described that the menstruating is much honored for women because menstruating is starting process to be a mother. She said, "Phul phulnu phal lagnu kati ramro ho testai ta ho chhau hunu pana" (just as flowering is for being fruits so is menstruating for being mother.).She was blaming the community for not considering menstruating as good rather it is taken as a sinful act and restricted from family and community. She argued if this Chhaupadi system lifts the restriction, then that would be very grateful for women.

\section{Changes in the System}

Even in this modern day, Chhaupadi system is pervasively exercised in Achham. The system penetrated in people's mind. Therefore, they could not change the system collectively. Cultural beliefs, religious values, and superstition on power of God are some major effective factors of continuation of Chhaupadi system (Karki \& Khadka, 2019).Some people still believe that a god or goddess become angry if the practice is not followed, which is cause of result in harm, death of livestock or destruction of crops (Gautam, 2017).

Supreme Court decided that Chhaupadi was discriminatory punitive act in 2005. And the parliament has recently passed a bill to criminalize the practice. Nevertheless, the decision has not ensured compliance, as the practice is still widely practiced in this area (Jun, 2018).The Guideline is the specific provision made for combating Chhaupadi problem in 2008. But it is not well-known even to district line agencies in all Chhaupadi affected region as well. The Ministry of Women, Child and Social Welfare promulgated it as per the Supreme Court directives for the Ministry. This guideline defines Chhaupadi, its effect, and need of action, objectives, and its mechanisms (Chary, 2017). Padma (name changed), a Community Mobilize, came to understand the negative effects of "Chhaupadi Pratha". She gave up following such practices and stayed in her home during menstruation. However, during this time, her goats were killed by wild animals. All of her family members believed that Chhaupadi was their norms. She refused to adhere to tradition. Then, she was treated as a bad woman who spoiled their family and the god. This fear reinforced her in the practices. She felt that the "god and goddess were not happy with her". She continued the practice again, despite some reluctance. When she appointed a community mobilizer of a local NGO, 
she worked on empowering women of the community. She learned more about women's and children's issues. Now, she, along with her family members, does not believe and follow such practices.

Likewise, women are somewhat leaving to stay in Chhaupadi Goth after Chhaupadi Goth free campaign conducted by local governments. Women started to use alternative shelter of Chhaupadi Goth. Some women stayed in the room attached with the house. But they don't enter at the house and kitchen. The women from the Chhaukhutte Bazar area are not following the system because of lack of availability of Goth and market penetration.

\section{Conclusion}

This study concludes that Chhaupadi system is still predominant practices of women in Duni village. The menstruate women continued to stay in small shed away from the home. Based on information in the, the women experienced various suffering and problems in the Goth. They felt isolated from the society. They were restricted from the dietary foods and dairy products. They have heavy workload because of the restriction from household work. They felt polluted and impure during periods. The belief of the local culture perpetuated the system of practiced in the community. Chhaupadi system is considered the process to maintain Dharma and protection from the Paap. Shamanism is also a triggering factor in the community. The Dhami is the main actor to describe the rules. People of the Achham do not consider Chhaupadi system as natural action but treated as a cultural construction (Amgain, 2011). The women felt that the system was making their status inferior in the community. Gender discrimination and violation of human rights of women were observed in the system. The study found that only the women are following the system. Men are the actors who force women to follow the system. These days, resistance campaigns against Chhaupadi are organized. Women felt psychologically and physically annoying for performing Chhaupadi system. Some changes in the system were observed and the causes of changes were the anti-Chhaupadi Goth campaign, education and other development activities.

\section{References}

Acharya, B. K. (2017). A Study of Chhaupadi Pratha (Menstrual Discrimination) in Nepal: Its Causes and Consequences. [Unpublished master's thesis] EwhaWomansUniversity.www.googlescholar.com.

Amity, P. Ghimire, S., Callahan, K. E., Baral, B.K., \& Poudel, K.C. (2018).Practice and lived experience of menstrual exiles (Chhaupadi) among adolescent girls in far-western Nepal.PLoS ONE 13(12).https://doi.org/10.1371/journal. 
Amgain, B. (2011). Social Dimension of Chhaupadi System Study from Achham District, Far West Nepal. Social Inclusion Research Fund (SIRF), SNV Nepal.

Bennett, L. (1983).Dangerous Wives and Sacred Sisters: Social and Symbolic Roles of High Caste Women in Nepal. New York: Columbia University Press.

Dahl, B.P., Chary, S., Munakarmi, R., Sunar, T. \& Parajuli, B. (2017).Chhaupadi and education of girls: A study on effects of Chhaupadi practices on education of adolescent girls in Karnali, Nepal. Kathmandu: Action Works Nepal \& BEE Group.www.googlescholar.com.

Douglas, M. (1966).Purity and Danger: an Analysis of the Concepts of Pollution and Taboo. New York: Routledge and Kegan Paul.

Gautam, Y. (2017). Chhaupadi: A Menstrual Taboo in Far Western Nepal. Journal of Nursing and Healthcare, 2(4), 1-4. www.googlscholar.com.

Husssain, N. (2011).Chaupadi pratha: tradition or torment?, Human Rights. http://www.restlessbeing.org/.

Joshi, L. R. (2015). "Chhaupadi Pratha: Socio-cultural Violence against Women in the Far Western Region of Nepal". Journal of Nepal Public Health Association, 6(1), 22-32.http://journal.nepha.org.np/images/Chhaupadi_Partha.pdf.

Jun, M. (2018). The Role of Social Capital in Shaping Policy Non-compliance for Chhaupadi Practice in Nepal. Asian Women, 34 (3), 47-70. https://doi.org/10.14431/aw.2018.09.34.3.47.

Kadariya, S. \& Aro, A.R. (2015).Chhaupadi practice in Nepal - analysis of ethical aspects. Medicolegal and Bioethics, 1-6. https://www.dovepress.com/.

Kandel, N., Bhandari, A. R. \& Lamichnne, J. (n. d.) "Chhue, Chhaupadi and Chueekula Pratha”-Menstrual Sheds: Examples of Discriminatory Practices against Women in the Mid-and Far-Western Regions of Nepal: Considering Women as "Impure" or "Unclean" During Menstruation and Post-Partum Periods, Nepal.http://nirmalkandel.com/wp-ntent/uploads/2014/03/Journal1.pdf.

Karki, T. B. \& Khadka, K. (2019). Social Discourses on Practices and Remedies of Harmful Tradition of Chhaupadi in Far Western Region of Nepal. Nepal Journal of Multidisciplinary Research (NJMR), 2 (1), 1-6.www.googlscholar.com.

$\mathrm{KC}, \mathrm{S}$. (2018).Impacts on social well-being of women due to the CHHAUPADI tradition (Being untouchable during menstruation) among the women of far western Nepal [Unpublished master's thesis] Oslo Metropolitan University.www.googlscholar.com.

Lama, D. \& Kamraj, R. (2015). Maternal and Child Health Care in Chhaupadi Pratha, Social seclusion of mother and child after delivery in Achham, Nepal. Public Health Research, 4, 22-33. www.googlscholar.com.

Maharjan, S. (2010). Chhaupadi Pratha: An Actus Reus. http://nepaenglish.com/. 
Mazzulo, Y. P.(2011). Chhaupadi Pratha: The taboo of menstruation: http://www.examiner.com/.

Rebaud, J. T. (2011). Monthly stigma: The practice of 'Chhaupadi' in Nepal. Ethics in Action, 5(5).http://www.ethicsinaction.asia/.

Sandbakken, L.D. (2011). The Practice of Chhaupadi: The Link between Local Cultural Understanding and Women's Rights in Rural Nepal. Norwegian University of Science and Technology, Faculty of Social Sciences and Technology Management, Department of Geography.www.googlescholar.com.

Sharma, R. (2010). Chhaupadi. Nyaya Health. http://blog.nyayahealth.org/. 